\title{
El águila y el dragón: el papel de las organizaciones transnacionales de inmigrantes en China y México
}

\author{
Alejandro Portes \\ Min Z $\mathrm{HOU}$ \\ (traducción del inglés de Luis Rodolfo Morán Quiroz)
}

Resumen. La literatura sobre el desarrollo en economía y sociología ha tendido a enfocarse en los flujos de capital, las inversiones y, más recientemente, en las instituciones como los principales factores causales. Tampoco considera las importantes sinergias para el desarrollo que producen las crecientes interacciones entre las organizaciones de inmigrantes y los gobiernos de los países de origen. Utilizando información de un estudio comparativo recientemente terminado, documentamos estos procesos para dos importantes países de emigración: México y China. El equipo del estudio generó inventarios de organizaciones de migrantes provenientes de los dos países hacia Estados, entrevistó a los líderes de las principales organizaciones y complementó estos datos con entrevistas a funcionarios y líderes comunitarios en cada uno de los países de origen.

Palabras clave: transnacionalismo, organizaciones de migrantes, remesas, desarrollo en México, desarrollo en China.

\begin{abstract}
Aвstract. The literature on development in economics and sociology has tended to focus on capital flows, investments, and, more recently, institutions as key causal factors. Nor does it consider important developmental synergies produced by the rising interactions between immigrant organizations and sending-country governments. Using data from a recently completed comparative study, we document these processes for two major countries of out-migration: Mexico and China. The study compiled inventories of migrant organizations from both countries in the United States, interviewed leaders of the major ones, and complemented these data with interviews with officials and community leaders in each sending country. Profiles of these transnational ties were constructed, exemplifying their increasing density and developmental impact at the local and national levels.
\end{abstract}

KEYwoRDs: transnationalism, immigrant organizations, remittances, Mexican development, Chinese development.

Alejandro Portes es doctor en Sociología por la Universidad de Wisconsin-Madison.

Min Zhou es profesora de sociología y estudios asiático-americanos en la Universidad de California. 


\section{INTRODUCCIÓN ${ }^{\mathrm{I}}$}

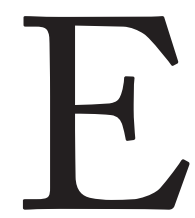
1 estudio de la migración y el desarrollo se ha centrado tradicionalmente en las fuerzas que expulsan a las personas desde sus regiones de origen, las consecuencias demográficas y sociales de su salida y los efectos subsecuentes de las remesas en las economías locales y regionales. La unidad de análisis normalmente ha sido el individuo migrante -identificado por la economía clásica como el principal encargado de la toma de decisiones en el proceso o la familia - privilegiado por la sociología y por la «nueva economía» de la migración como el determinante real de las decisiones de la migración. Al agregarse, las decisiones de los actores individuales y las unidades familiares pueden tener importantes efectos en las perspectivas sociales y económicos de los países y regiones de origen, así como de los países y regiones de recepción (Thomas, 1973; Borjas, 1990; Massey et al., 1998; Stark, 1991).

La literatura reciente sobre el transnacionalismo de los inmigrantes ha enfatizado los constantes contactos fluidos entre las comunidades de expatriados y sus localidades de origen, incluyendo la participación de los migrantes en actividades que requieren viajes regulares de ida y vuelta y frecuentes contactos por otros medios con sus contrapartes en el país de origen. $\mathrm{El}$ intenso tráfico tiende a opacarse por el énfasis en la asimilación de los

${ }^{11 /}$ La información en la cual se basa este artículo fue recolectada como parte del proyecto comparativo de organizaciones de inmigrantes (Comparative Immigrant Organization Project [ciop]) con apoyo de fondos provenientes de la Fundación Russell Sage y la Fundación MacArthur. Los autores agradecen el apoyo de los funcionarios del programa Aixa Cintron en Russell Sage y John Slocum en MacArthur, así como al presidente de la Fundación Russell Sage, Eric Wanner. La responsabilidad por el contenido es exclusivamente nuestra. 
inmigrantes en las sociedades receptoras, dejando de lado sus lazos duraderos con quienes se quedan en sus terruños (Vertovec, 2004; Landolt, Autler y Baires, 1999; Bauböck, 2003). La nueva escuela de los estudios transnacionales se centra en el individuo y en las familias. Una cantidad considerable de estudios de caso ha documentado las diversas y a veces sorprendentes formas que asumen estas actividades transfronterizas (Glick-Schiller y Fouron, 1999; Ostergaard-Nielsen, 2001; Itzigsohn y Saucido, 2002).

$\mathrm{El}$ énfasis predominante en el individuo y las familias ha pasado por alto un importante tercer actor: las organizaciones. Las iniciativas organizacionales de los propios migrantes y su entrelazamiento con los actores en el país de origen, incluyendo las comunidades, las regiones y los estados de origen, inciden directamente en la relación entre la migración y el desarrollo. Un importante estudio cuantitativo del transnacionalismo de los inmigrantes de América Latina, que analizó a los jefes de familia individualmente y su participación en las instituciones y actividades económicas, políticas y socioculturales en sus países de origen, arrojó un considerable cuerpo de hallazgos significativos. Este estudio identificó la mayor participación transnacional de los inmigrantes de mayor edad, con más escolaridad y más establecidos; encontró también que las actividades transfronterizas realizadas individualmente eran atípicas y que muchas de esas actividades se canalizaban a través de las organizaciones, incluyendo las asociaciones de oriundos (bometown associations) y las delegaciones de los partidos políticos del país de origen (Portes, Haller y Guarnizo, 2002; Guarnizo, Portes y Haller, 2003). El siguiente paso lógico es entonces analizar las organizaciones de inmigrantes y sus vínculos con los países de origen. En este artículo abordamos las siguientes preguntas: ¿cuáles son los tipos y la escala de las actividades transnacionales iniciadas por las organizaciones de inmigrantes? ¿Cómo son recibidas las iniciativas organizacionales y cómo son apoyadas por los países de origen? ¿Cómo inciden estas formas organizacionales en el desarrollo del lugar de origen? 


\section{Organizaciones TRANSNACIONALES Y}

DESARROLLO DEL LUGAR DE ORIGEN

Los gobiernos más alertas de los países de origen de los migrantes han establecido oficinas y programas que fortalecen los lazos y estimulan el diálogo con sus expatriados. Muchos lo han hecho a consecuencia de un cambio de énfasis en el pensamiento en torno al desarrollo. Tradicionalmente, los académicos y los diseñadores de políticas veían al desarrollo nacional como una derivación de la acumulación y la inversión de capital; más recientemente, el énfasis se ha trasladado a la calidad y la efectividad de las instituciones estatales (North, 1990; Evans, 2004; Hoff y Stiglitz, 2001; Iskander, 2010). Desde cualquiera de las dos perspectivas, la emigración ha sido considerada como un síntoma de subdesarrollo o, en el caso de los profesionales que migran, como una pérdida neta de talento - la llamada fuga de cerebros (Portes, 1976; Cheng y Bonacich, 1984). La posibilidad de que las comunidades de expatriados pudieran tener una influencia significativa en el progreso de los países de los que han salido rara vez se contempló en la economía o en la sociología (Ariza y Portes, 2007; Landolt, Autler y Baires, 1999).

El espectacular aumento de las remesas de los migrantes ha cambiado este estado de cosas. Las remesas de los migrantes se incrementaron desde un estimado total global de 43.3 mil millones de dólares en 1980 a 100 mil millones de dólares en 2000 (Gammeltoft, 2002; Guarnizo, 2003). Para 2008, las remesas oficialmente registradas hacia los países en desarrollo alcanzaron 336 mil millones; los principales receptores de las remesas de los migrantes fueron India (49 mil millones), China (48 mil millones), México (22 mil mi1lones) y Filipinas (20 mil millones) (Banco Mundial, 2010). Parecía que de la noche a la mañana los gobiernos de los países de origen descubrieron que sus nacionales en el extranjero estaban haciendo contribuciones en divisas duras que en muchas instancias excedían con mucho lo que sus países recibían en ayuda extranjera, y que con frecuencia rivalizaba con las ganancias de sus prin- 
cipales exportaciones mercantiles (Massey, Durand y Malone, 2002; Portes, Escobar y Radford, 2007). El Banco Mundial y otras agencias internacionales respondieron con análisis de flujos de remesas y planes para canalizarlos hacia inversiones productivas. Los flujos anuales de remesas cobraron prominencia en las cuentas nacionales de los países de salida de los migrantes y fueron utilizadas incluso como factores colaterales para las negociaciones de los préstamos externos (Delgado Wise y Márquez, 2006; Guarnizo, 2003).

Los gobiernos de los países de origen descubrieron, igualmente, que además de las remesas, los expatriados estaban haciendo contribuciones filantrópicas que con frecuencia eran de millones de dólares para sus terruños y transferencias significativas de tecnología y estrategias comerciales a sus contrapartes en los países de origen (Saxenian, 2002, 2006; Goldring, 2002). Para sostener, estimular y guiar esas transferencias, los gobiernos de los países de origen comenzaron a interactuar con sus expatriados. No lo hicieron a través de los individuos, sino por medio de los representantes de las organizaciones creadas por los propios migrantes. Las organizaciones de migrantes se tornaron así en el foco principal de la atención oficial más o menos al mismo tiempo que los académicos de la inmigración estaban descubriendo las dinámicas del transnacionalismo y, muy anticipadamente, respecto al descubrimiento de que estos fenómenos estaban difundidos mucho más allá de los individuos para incluir a redes de organizaciones cada vez más densas (Vertovec, 2004, 2009; Vermeulen, 2005; Delano, 2011).

La literatura del desarrollo sigue enfocada en las remesas de los individuos, dejando de lado las formas más amplias de organización de los migrantes y sus actividades. De manera similar, la literatura de la inmigración documenta las muchas formas de transnacionalismo individual y familiar, pero en gran medida ignora la estructura organizacional de las comunidades de expatriados y su diálogo creciente con los gobiernos de sus países de origen (Portes, Escobar y Radford, 2007; Iskander, 2010). No todos los gobiernos han iniciado o participado en estas actividades: los Estados de origen más débiles o menos diligentes se han conformado con dejar pasivamente que 
fluyan las remesas, con escasa acción de su parte. Sin embargo, las actividades proactivas de los Estados más alertas y sus interacciones cada vez más complejas con sus nacionales en el extranjero han abierto un nuevo capítulo en el estudio del desarrollo, a la vez que han proporcionado una nueva lente en cuanto a la adaptación de las comunidades migrantes a sus nuevos ambientes.

Las sociedades receptoras también están reaccionando a este creciente tráfico transnacional, aunque sus políticas no han sido uniformes. Algunos gobiernos en los países receptores han reaccionado positivamente a sus esfuerzos a favor del desarrollo de parte de los grupos de inmigrantes en sus espacios, mientras que otros han visto estas actividades como una forma de retrasar el proceso de asimilación o incluso como una forma de poner en riesgo la seguridad nacional (Freeman, 2004; Hollifield, 2004). Regresaremos a ese tema en nuestra conclusión.

\section{Metodología}

La creciente importancia de las organizaciones de inmigrantes incitó a un equipo de investigación con sede en la Universidad de Princeton a lanzar el Proyecto Comparativo de las Organizaciones de Inmigrantes (Comparative Immigrant Organization Project [CIOP]) para analizar su presencia y actividades entre las comunidades de expatriados en Estados Unidos. Algunos valiosos estudios de caso precedieron este esfuerzo, como el trabajo de Goldring (2002) sobre las federaciones de inmigrantes mexicanos y el de Landolt, Autler y Baires (1999) sobre las asociaciones salvadoreñas. Hasta la creación del ciop, sin embargo, ni se habían compilado directorios globales de las organizaciones de inmigrantes con sede en Estados Unidos y de sus tipos, ni se habían realizado entrevistas cara a cara con los líderes de los grupos más importantes. Utilizamos los datos de este proyecto para describir y comparar las organizaciones creadas por los inmigrantes provenientes de dos fuentes principales de la migración hacia Estados Unidos: México y China. 
El diseño de investigación para el estudio requirió desarrollar directorios de las asociaciones para cada nacionalidad de inmigrantes y clasificarlas por tipo, con atención especial a la diferencia entre las que participan en programas enfocados únicamente en las necesidades internas de las comunidades de inmigrantes y aquellas que participan en actividades transnacionales. Este esfuerzo fue apoyado por el personal consular de los dos países de origen, los líderes de las federaciones más amplias e informantes expertos. Los entrevistados también ofrecieron información para explorar otras asociaciones, lo que ayudó a completar cada directorio nacional. En el proceso de construir los directorios, los investigadores lograron identificar las organizaciones de mayor tamaño y las más estables que operan con una perspectiva transnacional. Los líderes de las aproximadamente 30 de mayor tamaño fueron luego seleccionados para entrevistas en persona.

Encontramos que la estructura organizacional de cada comunidad inmigrante estaba compuesta de unas cuantas federaciones y agencias de servicio social grandes y relativamente bien financiadas, seguidas por una multiplicidad de asociaciones de menor tamaño, algunas de las cuales se las arreglan para sobrevivir en el tiempo, mientras que otras surgían y desaparecían en un lapso breve. El tamaño y la longevidad fueron usados como criterios para la selección de la muestra bajo la suposición de que las organizaciones de mayor tamaño, de mayor edad y mejor establecidas son las más capaces de iniciar proyectos de desarrollo en los países de origen y de establecer el diálogo con los gobiernos de los países de origen.

La parte final del diseño de investigación requirió viajar a cada uno de los países de origen para entrevistar a los funcionarios de gobierno responsables de conservar los lazos con las comunidades de expatriados y para reunirse con las contrapartes institucionales locales de las organizaciones contactadas en Estados Unidos. Estas entrevistas cumplieron un doble propósito: primero, poner a prueba la confiabilidad de los informes acerca de los programas y actividades realizadas en Estados Unidos por los líderes de los inmigrantes; segundo, completar la imagen al tener una perspectiva desde el

1124 MIGRACIÓN Y DESARROLLO, VOL. 11, NÚM. 20, PRIMER SEMESTRE DE 2013 
país de origen en cuanto al impacto en el desarrollo de las actividades transnacionales. Las entrevistas en los países de origen tomaron un promedio de tres meses por país y fueron realizadas, entre 2006 y 2008, en México y en otros países latinoamericanos, y entre 2009 y 2010 en China. Se realizaron 35 entrevistas con funcionarios federales, líderes comunitarios e informantes expertos de origen mexicano; en China, se realizaron 62 entrevistas.

Originalmente se identificaron tres grupos de inmigrantes latinoamericanos para el estudio de Princeton: los provenientes de Colombia, República Dominicana y México. Los mexicanos constituyen el grupo más numeroso y más antiguo de los tres grupos de inmigrantes y su país de origen el de mayor tamaño y de mayor importancia económica. Desde que se estableció el Tratado de Libre Comercio de América del Norte (TLCAN) en 1994, las economías de Estados Unidos y México se han entrelazado cada vez más, convirtiéndose México en una plataforma crucial para la producción de automóviles y otros productos industriales para el mercado estadounidense (Shaiken, 1994; Delgado Wise y Márquez, 2006). Por esta razón, centramos nuestro análisis en México, mientras que sintetizamos los hallazgos de los otros dos países latinoamericanos cuando resulta relevante.

El estudio combinó una aproximación cuantitativa a la cantidad y tamaño de las organizaciones de inmigrantes con un enfoque cualitativo en las visiones y actividades de sus líderes y de sus contrapartes en el país de origen. Los informativos resultados que obtuvimos con esta metodología transnacional llevó al equipo de investigación a ampliarla hacia los más grandes grupos asiáticos de inmigrantes. Siguiendo la misma metodología compilamos un inventario de las organizaciones de inmigrantes chinos en todo el país, pero concentrándonos en las tres principales áreas urbanas de concentración de inmigrantes chinos: Los Ángeles, San Francisco y Nueva York. A partir de este inventario seleccionamos las 55 organizaciones más grandes y estables para ser examinadas a detalle y para entrevistar a sus líderes.

En China, las entrevistas con los funcionarios de gobierno y del partido se realizaron en los ámbitos nacional, regional y local, pero las observacio- 
nes de las contrapartes del país de origen estuvieron limitadas a las provincias de Guangdong y Fujian, que son abrumadoramente las fuentes principales de la inmigración china histórica y contemporánea hacia Estados Unidos. 12 entrevistas se realizaron en Beijing y 50 más en los niveles provincial y local. ${ }^{2}$ China es el principal competidor de México en la producción y exportación de bienes hacia Estados Unidos (Iranzo y Alyson, 2006) y los dos países han seguido trayectorias paralelas en la generación de flujos de salida de migrantes hacia Estados Unidos durante más de un siglo. Ambos han abiertos sus economías a la inversión y el comercio extranjeros durante las últimas tres décadas. Dadas sus importantes vínculos económicos con Estados Unidos y el tamaño de sus comunidades de expatriados en América del Norte, resulta importante comparar el carácter de sus respectivas organizaciones de inmigrantes y su incidencia en los desarrollos nacional y regional de los países de origen. Una consideración adicional remite a la manera en que las autoridades de Estados Unidos han reaccionado a esta proliferación de actividades transnacionales entre las principales comunidades de inmigrantes en ese país, un asunto que retomaremos en la sección de conclusiones.

\section{OrganizaCiONES TRANSNACIONALES MEXICANAS Y DE OTROS PAÍSES LATINOAMERICANOS}

Los mexicanos, como hemos señalado, constituyen el grupo de inmigrantes contemporáneo de mayor tamaño en Estados Unidos, alcanzando cerca de 11.5 millones en 2010 y representan cerca de una tercera parte de la pobla-

${ }^{12 /}$ Tuvimos una discusión de grupo de foco con cuatro funcionarios en la Oficina China de Asuntos Exteriores (Qiao-ban) del Consejo Estatal y con funcionarios de la Federación del Partido Comunista de los Chinos de Retorno del Extranjero (Qiao-lian) en Beijing. También entrevistamos a los directores o delegados provinciales de Qiao-ban

\footnotetext{
1144 MIGRACIÓN Y DESARROLLO, VOL. 11, NÚM. 20, PRIMER SEMESTRE DE 2013
} 
ción nacida fuera del país. Históricamente y en la actualidad, México ha funcionado como la principal reserva de trabajo manual para su vecino del norte. El final del Programa Bracero en 1964 derivó en la canalización clandestina de este flujo de fuerza de trabajo y el rápido crecimiento de la categoría de inmigrantes ilegales o no autorizados (Massey y Pren, 2012). Se estima que más de un tercio de los inmigrantes mexicanos en Estados Unidos en el presente se ubican en esta categoría (Passel, 2009; Massey, 2007).

Los inmigrantes provenientes de México tradicionalmente se han concentrado en el suroeste de Estados Unidos y, en segundo lugar, en el medio oeste; $37 \%$ de los inmigrantes mexicanos viven en California, $21 \%$ en Texas y 6\% en Illinois (Pew Hispanic Center, 2011). En años recientes, la fuerza de trabajo mexicana se ha trasladado hacia el este en busca de empleo en la agricultura y la industria y para escapar de la creciente vigilancia de la frontera en el oeste. Esto ha llevado a grandes incrementos de la población de origen mexicano en los estados en los que hace apenas unos años era inexistente. Nueva York, Nueva Jersey y estados del sur como Georgia y Carolina del Norte y del Sur han sido receptores de este desplazamiento masivo de mano de obra (Smith, 2005; Ansley y Shefner, 2009).

Las organizaciones de inmigrantes mexicanos en Estados Unidos son diferentes respecto de las creadas por otros grupos latinoamericanos en varios aspectos clave. La población inmigrante de origen mexicano no sólo es mayor que todos los otros grupos latinoamericanos combinados, sino que es predominantemente rural (Cornelius, 1998; Ariza y Portes, 2007; Arias, 2008). Las lealtades tradicionales a los lugares de origen derivan en una proliferación

y Qiao-lian en Guangdong y Fujian. Estas entrevistas fueron seguidas por reuniones similares con los directores o delegados de Qiao-ban en las ciudades de Fuzhou, Fuqing, Changle y Lianjiang en la provincia de Fujian, y Guangzhou, Jiangmen, Taishan, Kaiping y Zhongshan en la provincia de Guangdong. También visitamos y entrevistamos a las autoridades de 16 aldeas de origen de migrantes en estas dos provincias. 
de asociaciones cívicas de oriundos mucho más durables y numerosas que las creadas por otros grupos de inmigrantes. Mientras que otras organizaciones de inmigrantes latinos dependen de rifas, bailes y acontecimientos similares para recolectar fondos, los inmigrantes mexicanos contribuyen regularmente a sus asociaciones de oriundos y ven a esas contribuciones como una continuación de sus deberes tradicionales (cargos) hacia sus lugares de origen (Sánchez, 2007).

TABLA I

Distribución porcentual de las organizaciones de inmigrantes latinoamericanos en Estados Unidos por país de origen y tipo.

\begin{tabular}{lrrrr}
\hline \multicolumn{1}{c}{ Tipo } & Colombia & República Dominicana & México & Total \\
\hline Organización cívica/cultural & 47.3 & 30.0 & 6.8 & 16.2 \\
Otra organización cultural & 10.2 & 15.3 & 0.5 & 3.7 \\
Organización económica & 4.4 & 2.4 & 0.7 & 1.5 \\
Asociación de oriundos & 1.9 & 3.5 & 63.8 & 47.0 \\
Federaciones de asociaciones de oriundos & 0.0 & 0.0 & 4.3 & 3.1 \\
Asociación por estado de origen & 0.3 & 1.2 & 8.7 & 6.5 \\
Organización filantrópica internacional & & & & \\
(Leones, Rotarios, Kiwanis) & 7.0 & 3.5 & 0.0 & 1.6 \\
Filantropía del país de origen & & & & \\
Comité político & 3.2 & 0.0 & 0.0 & 0.6 \\
Asociación profesional & 7.9 & 10.0 & 0.5 & 2.7 \\
Grupo religioso & 8.9 & 14.1 & 0.7 & 3.4 \\
Agencia de servicio social & 1.6 & 1.9 & 0.2 & 0.6 \\
Grupo deportivo & & 2.9 & 17.1 & 3.3 \\
Organización estudiantil & 0.6 & 1.8 & 10.0 & 7.6 \\
Total & 3.8 & 0.0 & 0.5 & 1.1 \\
$\mathrm{~N}$ & 100.0 & 100.0 & 100.0 & 100.0 \\
\hline
\end{tabular}

Nota: las organizaciones fueron clasificadas según la definición de sí mismas proporcionada por sus líderes y sus materiales publicados.

Fuente: Banco de datos del Comparative Immigrant Organización Project (crop), Princeton Center for Migration and Development, http://www.princeton.edu/cmd/s. 
La tabla 1 muestra los tipos y cantidades de organizaciones de inmigrantes recabadas entre las tres nacionalidades latinoamericanas incluidas originalmente en el estudio de Princeton. La tipología de organizaciones en esta tabla se basa en las definiciones de sus propios líderes más que en una clasificación a priori de parte del equipo de investigación. Las organizaciones mexicanas son mucho más numerosas que las de Colombia y República Dominicana y son predominantemente asociaciones de oriundos. Dos terceras partes de los grupos de mexicanos quedan en esta categoría, en comparación con una cifra menor a $4 \%$ entre los dominicanos y $2 \%$ entre los colombianos. Las federaciones de asociaciones de oriundos, agrupadas por estados de origen, equivalen a otro $4 \%$ de las organizaciones mexicanas, mientras que no existen entre las otras dos nacionalidades incluidas en el estudio.

La fuerte y proactiva presencia del gobierno mexicano en el campo transnacional es notable. Varios estados mexicanos, comenzando por Zacatecas, crearon federaciones de comités de oriundos a todo lo largo y ancho de Estados Unidos a principios de los años noventa. El gobernador de Zacatecas, los alcaldes de sus principales ciudades y los legisladores del estado viajan frecuentemente a Los Ángeles, Houston y otras ciudades para generar lazos con los líderes de las federaciones de inmigrantes, quienes, a su vez, visitan regularmente su estado. Zacatecas fue líder y un fuerte soporte para el Programa 2x1, ahora 3x1, según el cual por cada dólar donado por las organizaciones de inmigrantes para obras públicas en México se le añaden un dólar de los gobiernos federal, estatal y municipal, cuadruplicando así el impacto de estas inversiones filantrópicas (Goldring, 2002; Guarnizo, 2003; De la Garza y Hazan, 2003).

Según el gobernador de Zacatecas, el programa 3x1 ha apoyado a más de mil proyectos en el estado. Salones de clase, áreas de juegos infantiles y carreteras se han construido con estos fondos. Se calcula que unos $600 \mathrm{mil}$ residentes de Zacatecas viven en Estados Unidos, lo que equivale a grandes rasgos a $40 \%$ de la población del estado a fines de los años noventa. El programa $3 \times 1$ constituye uno de los principales medios para convertir un declive 
demográfico rampante en una fuerza positiva de desarrollo para el estado. El gobierno también ha instituido el Programa Por los que Regresan, que ofrece becas a los jóvenes zacatecanos en el extranjero para que vuelvan a estudiar al estado (Joffe-Block, 2010).

Otros estados de origen, como Jalisco y Michoacán, han adoptado el modelo zacatecano y promovido la creación de las federaciones de oriundos en los centros de concentración de migrantes mexicanos como Los Ángeles, Chicago y Houston durante los años noventa. El ejemplo ha sido seguido más recientemente, en la mayoría de los casos, con la ayuda de los consulados mexicanos y los gobiernos estatales, de parte de los migrantes que se dirigen a destinos no tradicionales. De esa forma, en Nueva York, donde la población mexicana proviene predominantemente del estado de Puebla, las organizaciones comunitarias recibieron un fuerte apoyo del consulado mexicano y del gobierno del estado de Puebla para crear la Casa Puebla en la ciudad de Nueva York. Desde 1994, el estado de Guanajuato ha apoyado el establecimiento de 45 Casas Guanajuato en 14 estados de Estados Unidos, incluyendo cinco en la costa este (Escobar, 2007).

La presencia del gobierno federal mexicano es aun más influyente en el campo transnacional. Ésta ha asumido la forma de programas para igualar las contribuciones filantrópicas de los migrantes, más recientemente el Programa 3x1; la creación de plazas comunitarias en varias ciudades de Estados Unidos que ofrecen servicios de biblioteca, información y cursos de idiomas (inglés y español) para los mexicanos; el fortalecimiento de los programas de defensa legal para los inmigrantes por medio de una red de 55 consulados en Estados Unidos y Canadá; la creación de una matrícula consular, una tarjeta de identificación mexicana que es aceptada por los bancos y otras agencias en Estados Unidos, y la creación de «ventanillas de salud» en varios de estos consulados, proporcionando servicios médicos básicos e información para los migrantes mexicanos.

La creación del Instituto de los Mexicanos en el Exterior (IME) representa la culminación de estos esfuerzos. El IME, con sede en la Secretaría de 
Relaciones Exteriores del gobierno mexicano, organiza reuniones bianuales de su consejo consultivo de 125 representantes electos de las organizaciones de inmigrantes en Estados Unidos y Canadá (González Gutiérrez, 2005; Delano, 2011). El gobierno mexicano se ha fortalecido para apoyar y estimular a nivel nacional estas iniciativas. A través de docenas de consulados mexicanos en Estados Unidos y Canadá, el IME conduce un programa para involucrar a los migrantes mexicanos, defender sus intereses y promover la continuación de sus lazos con México. El propósito general del IME es promover la continuidad de los lazos de los migrantes con sus terruños al mismo tiempo que facilitar su integración en las comunidades estadounidenses por medio de programas como el de aprendizaje del idioma inglés y la educación cívica. Esta aproximación no beligerante ha llevado al IME a colaborar activamente con los gobiernos municipales y estatales de Estados Unidos y Canadá en programas de asistencia a los trabajadores migrantes (González Gutiérrez, 2005; Delano, 2011). La figura 1 ilustra el denso tráfico transnacional entre México y sus comunidades de expatriados.

El transnacionalismo mexicano es, pues, diferente del que profesan otras comunidades de inmigrantes latinos, una diferencia que puede rastrearse hasta los contextos de salida e incorporación de los inmigrantes. Siendo un flujo de fuerza de trabajo principalmente rural y frecuentemente indígena, la baja escolaridad y los bajos ingresos de estos inmigrantes evitan que creen formas de organización más similares a las de clase media. No puede esperarse que surjan clubes de «Leones» o «Kiwanis», como los creados por los inmigrantes colombianos (véase tabla 1 ), de los migrantes de orígenes rurales que ocupan las posiciones más bajas del mercado de fuerza de trabajo estadounidense (Portes, Escobar y Radford, 2007). En cambio, las lealtades y deberes tradicionales se activan para reunir a los inmigrantes mexicanos y sostener vibrantes lazos con sus pueblos de origen. Es frecuente que incluso los inmigrantes no autorizados encabecen comités de oriundos y dediquen muchas horas y dólares duramente devengados para este esfuerzo (Goldring, 2002; Roberts, Frank y Lozano-Asencio, 1999; D’Aubeterre, 2007). 
FIGURA I

Conexiones transnacionales de las organizaciones de inmigrantes mexicanos: ejemplos seleccionados

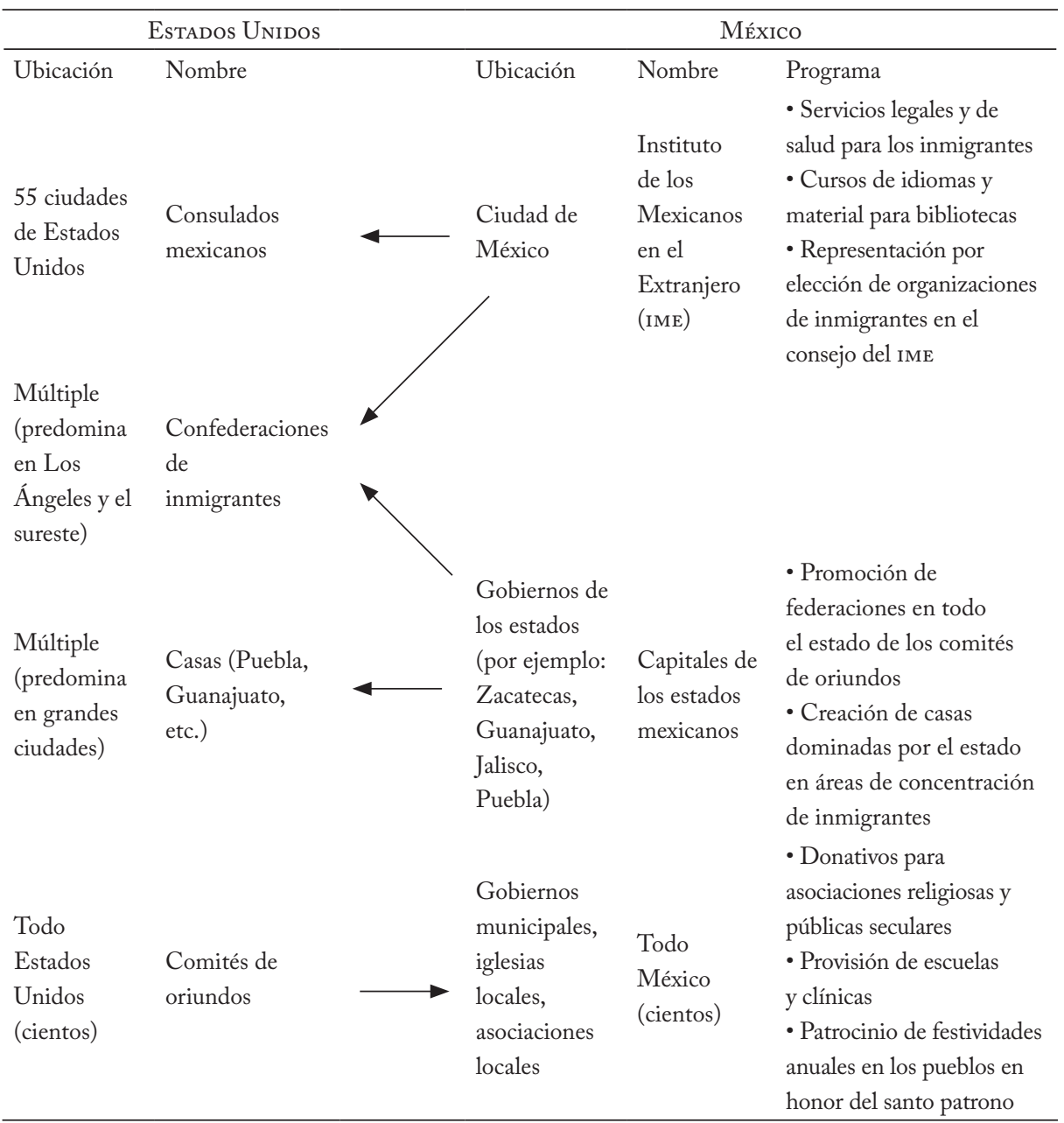

Nota: las flechas indican la dirección transnacional predominante de los programas enumerados en la columna de la extrema derecha.

Fuente: Comparative Immigrant Organización Project (ciop). 
TABLA 2

Características de los miembros de las organizaciones de inmigrantes latinoamericanos en Estados Unidos según nacionalidad (porcentajes).

\begin{tabular}{|c|c|c|c|c|}
\hline & Colombianos & Dominicanos & Mexicanos & $\begin{array}{l}\text { Total en } \\
\text { ciop }\end{array}$ \\
\hline \multicolumn{5}{|l|}{ Edad } \\
\hline 30 años o menores & 12.1 & 11.1 & 24.8 & 15.2 \\
\hline 40 años o mayores & 53.2 & 53.8 & 33.6 & 48.3 \\
\hline \multicolumn{5}{|l|}{ Escolaridad } \\
\hline Inferior a educación media & 7.4 & 29.7 & 28.7 & 20.9 \\
\hline Licenciatura o posgrado & 52.3 & 50.5 & 27.0 & 45.7 \\
\hline \multicolumn{5}{|l|}{ Ocupación } \\
\hline Trabajador manual & 18.0 & 26.4 & 40.1 & 26.6 \\
\hline Profesional/empresario & 49.8 & 61.5 & 36.0 & 50.3 \\
\hline \multicolumn{5}{|l|}{ Conocimiento del inglés } \\
\hline Muy poco & 11.9 & 18.7 & 5.0 & 12.4 \\
\hline Bueno o muy bueno & 64.2 & 49.7 & 60.9 & 58.5 \\
\hline \multicolumn{5}{|l|}{ Status legal } \\
\hline No cuenta con visa de ingreso & 6.3 & 3.5 & 27.9 & 10.7 \\
\hline Ciudadano estadounidense & 56.3 & 48.5 & 38.4 & 49.1 \\
\hline \multicolumn{5}{|l|}{ Tiempo estancia EUA } \\
\hline Menos de 5 años & 10.1 & 5.8 & 10.4 & 8.7 \\
\hline 10 años o más & 68.9 & 66.8 & 69.5 & 69.3 \\
\hline \multicolumn{5}{|c|}{ Frecuencia promedio de los viajes de los } \\
\hline \multirow{2}{*}{\multicolumn{5}{|c|}{$\begin{array}{l}\text { líderes al país de origen por asuntos de la } \\
\text { organización }\end{array}$}} \\
\hline & & & & \\
\hline Nunca o rara vez & 6.7 & 3.6 & 30.0 & 11.5 \\
\hline $\mathrm{Al}$ menos tres viajes al año & 40.0 & 35.7 & 20.0 & 33.3 \\
\hline $\mathrm{N}$ & 50 & 56 & 133 & 247 \\
\hline
\end{tabular}

Nota: número de organizaciones cuyos líderes fueron entrevistados en persona o por teléfono.

Fuente: Banco de datos del Comparative Immigrant Organización Project (сіо)), Princeton, Center for Migration y Development, http://www.princeton.edu/cmd/s. 
Un análisis de los determinantes del surgimiento de las organizaciones transnacionales de inmigrantes realizado con base en la muestra del ciop indicó que el patrocinio del gobierno de origen es bastante escaso entre los otros grupos de latinoamericanos, pero bastante común entre los inmigrantes mexicanos. Las organizaciones mexicanas tenían una tendencia a ser creadas gracias al patrocinio oficial diez veces superior que las colombianas o dominicanas (Escobar, 2010; Portes, Escobar y Radford, 2007). Este resultado refleja nuevamente una cooperación única del Estado mexicano con sus comunidades de expatriados. No obstante, los resultados del estudio muestran también que la preponderancia de las organizaciones transnacionales entre las nacionalidades latinoamericanas surgió por iniciativa de los propios inmigrantes, más que por petición de sus gobiernos.

Un último conjunto de hallazgos estaba relacionado con las características de los miembros de las organizaciones transnacionales. La tabla 2 presenta estos hallazgos, mostrando que las organizaciones son apoyadas de forma consistente por los migrantes de más edad, con mayor escolaridad y más establecidos en sus comunidades. Aproximadamente la mitad de los miembros regulares de Colombia y la República Dominicana tenían 40 años o más de edad y contaban con al menos una licenciatura, en contraste con una quinta parte o menos que tenían menos de 30 años de edad o tenían una escolaridad inferior a la educación media. En comparación con las asociaciones colombianas y dominicanas, las organizaciones mexicanas atraían a una proporción mayor de jóvenes y contaban con una cantidad similar de personas con baja escolaridad y de personas con alta escolaridad. Este resultado es consistente con la estructura de edad juvenil y por lo general bajos niveles de escolaridad de la población mexicana migrante en conjunto; también refleja las lealtades duraderas de los migrantes mexicanos pobres con sus orígenes rurales, lo que los lleva a crear comités de oriundos en gran cantidad.

La tabla 2 también muestra que cerca de $70 \%$ de los miembros de todas las organizaciones latinoamericanas de inmigrantes han vivido en Estados Unidos por 10 años o más y la mitad de ellos se han convertido en ciudadanos 
de Estados Unidos. Una excepción parcial la constituyen una vez más las asociaciones mexicanas, que consiguen una cuarta parte de sus cifras a partir de los inmigrantes no autorizados; incluso entre ellos, empero, los ciudadanos naturalizados en Estados Unidos superan a los no autorizados. A partir de estos resultados concluimos que la motivación para participar en actividades transnacionales entre los inmigrantes mexicanos y de otros países latinoamericanos se encuentra primordialmente entre los miembros de mayor escolaridad de las comunidades y entre aquéllos con periodos más prolongados de residencia en Estados Unidos y un estatus legal más seguro. En este proceso los migrantes recientes buscan establecer un nicho para sí mismos en la sociedad y en el mercado de trabajo de recepción, más que ocuparse de los esfuerzos colectivos. En su mayoría, las iniciativas colectivas surgen e influyen en las localidades y países de origen únicamente después de haber completado con éxito las etapas iniciales de adaptación económica y social de los migrantes. Los datos del estudio de Princeton mostraron que los inmigrantes con mayor probabilidad de participar en las organizaciones transnacionales eran también los más inclinados a participar en las asociaciones políticas locales y en las asociaciones cívicas en Estados Unidos (Portes, Escobar y Arana, 2008; Escobar, 2007).

\title{
EL TRANSNACIONALISMO
}

\section{MEXICANO EN MOVIMIENTO}

\begin{abstract}
Durante la última década, Armando Fernández ha contribuido a recabar decenas de miles de dólares para proyectos de obras públicas en su pueblo natal, San Juan del Centro, Jerez, Zacatecas. Armando Fernández es ingeniero civil y vive en Corona, California, como ciudadano estadounidense formó un club con otros migrantes para beneficiar a su terruño. Comenzó haciendo mejoras a la escuela primaria a la que alguna vez asistió Fernández y siguió con otras numerosas contribuciones. Es la cuarta generación de su familia que lleva una vida transnacional (Joffe-Block, 2010: 18).
\end{abstract}


El primer logro de la asociación de oriundos de San Miguel Comitipla en el estado de Guerrero, establecida por sus migrantes en Nueva York, fue el quiosco construido en la plaza central. Posteriormente se reparó y redecoró la iglesia local y se compró un enorme reloj para su torre. La calzada o avenida que desemboca en la plaza fue reparada con adoquín. Para estos proyectos se combinaron las contribuciones financieras de los migrantes con la fuerza de trabajo local voluntaria. El siguiente proyecto de envergadura que está en ciernes (en 2005) es la expansión de la plaza para tener espacio para la fiesta anual del pueblo. Se espera que cueste cerca de 80 mil dólares y, con una cubierta adicional, 260 mil dólares. Aunque los comités de oriundos no son explícitamente religiosos, es común que los primeros proyectos que se logran con las contribuciones sean la reparación del templo del pueblo y su entorno. El alcalde a cuyo municipio pertenece San Miguel Comitipla describió los inicios de esta empresa:

\begin{abstract}
Aproximadamente en 1985 comenzaron las obras en beneficio de nuestro pueblo. Todas eran de carácter religioso para mejorar el santuario de San Diego de Alcalá, el santo patrono más respetado en los alrededores; luego compramos los arbotantes para la avenida en que se da la procesión. En la actualidad y con la ayuda de los migrantes en Estados Unidos, las obras públicas están muy avanzadas: el templo está en buenas condiciones, redecorado y con hoja de oro en los altares; ahora buscamos reconstruir la escuela con el apoyo del municipio y de la gente que tenemos en Estados Unidos. ${ }^{3}$
\end{abstract}

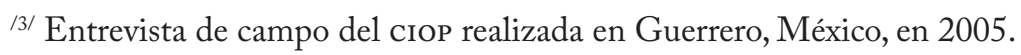

124 MIGRACIÓN Y DESARROLLO, VOL. 11, NÚM. 20, PRIMER SEMESTRE DE 2013 


\section{LAS ORGANIZACIONES TRANSNACIONALES \\ DE ORIGEN CHINO}

China cuenta con una población estimada en 1.3 mil millones, la mayor en el mundo. Su diáspora, compuesta por los inmigrantes chinos y su descendencia, se estima en 48 millones, una de las más numerosas del mundo. El grueso de esta población diaspórica se encuentra en el sureste de Asia. Estados Unidos cuenta con una población de etnia china de unos 3.8 millones, la más grande de los grupos no europeos, con excepción de los mexicanos. Los inmigrantes de primera generación constituyen dos terceras partes de esta población.

La inmigración china hacia Estados Unidos comenzó a mediados del siglo xix en respuesta a un activo reclutamiento de fuerza de trabajo para la minería, construcción de ferrocarriles y agricultura. Los trabajadores chinos se encontraban en grandes cantidades en estas actividades hasta que el Decreto de Exclusión de los Chinos (Chinese Exclusion Act) de 1882 acabó con el flujo (Saxton, 1971; Chan, 1986; Zhou, 2009). Los chinos y, en menor medida los japoneses, fueron pronto reemplazados por campesinos mexicanos que también fueron reclutados deliberadamente para trabajar en las mismas actividades. En muchos lugares del oeste y del suroeste estadounidense seguramente coincidieron grandes cantidades de trabajadores mexicanos y chinos al inicio del siglo xx (Barrera, 1980; García, 1981; Romero, 2010).

A diferencia de la migración mexicana del periodo previo, que era en gran parte temporal, los inmigrantes chinos, que en una alta proporción eran hombres, permanecieron en América por periodos de tiempo indefinidos, aun cuando no pretendieran quedarse permanentemente. Sujetos a discriminación racial y a la exclusión legal, se reunieron en enclaves urbanos desempeñando los tipos más bajos de trabajos menores. Estas sociedades de solteros, estrechamente entretejidas, constituyeron los antecedentes de los actuales barrios chinos (Chinatowns) en muchas ciudades estadounidenses, en particular en California y Nueva York (Nee y Nee, 1973; Chan, 1986; Zhou, 1992). 
La inmigración china es notable por sus lugares de origen. La emigración previa se originó en gran medida en dos provincias del sur, Guangdong y Fujian. Guangdong, la segunda provincia en población de China, constituyó la mayor fuente de las migraciones chinas y prácticamente el único origen de la migración hacia Estados Unidos entre fines de la década de 1840 y hasta la década de 1940. En la actualidad, se calcula que unos 30 millones de personas de origen étnico chino en el extranjero — más de la mitad del total- reconocen sus orígenes en Guangdong. Las principales fuentes de emigración hacia América del Norte incluyen las ciudades de Jiangmen, ${ }^{4}$ Zhongshan y las áreas rurales circundantes en el Delta del Río Perla. Fujian ha sido históricamente la segunda gran fuente de las migraciones chinas. Los migrantes de origen en Fujian han ingresado a Estados Unidos desde el comienzo del siglo xx, pero el flujo se aceleró a fines de la década de 1980, notablemente por medio de las actividades de contrabandistas organizados —los llamados snakeheads (Chin, 2000)—. Cerca de nueve millones de chinos en el extranjero reconocen sus orígenes en Fujian. Las principales ciudades de origen hacia Estados Unidos incluyen Lianjiang, Changle, Fuqing y la capital, Fuzhou (Zhou, 2010).

\section{Desarrollo organizacional}

\section{EN LOS ANTIGUOS BARRIOS CHINOS}

Durante el último cuarto del siglo xix y buena parte del xx, los chinos en Estados Unidos fueron segregados en barrios chinos en la costa oeste y en otras ciudades estadounidenses de importancia como Nueva York y Chicago. Aunque se les aislaba de la sociedad más amplia, estas comunidades étnicas

${ }^{14 /}$ Conocido como Wuyi qiao-xiang, engloba cuatro condados de origen: Taishan, Kaiping, Enping, Heshan y Xinhui.

126 MIGRACIÓN Y DESARROLLO, VOL. 11, NÚM. 20, PRIMER SEMESTRE DE 2013 
- compuestas principalmente de trabajadores varones- no estaban ni atomizadas, ni desconectadas de los acontecimientos políticos y sociales en China. En 1900 la proporción de chinos varones frente a la de mujeres en Estados Unidos era aproximadamente de 27 . Más de $60 \%$ de esta población se concentraba en California, donde sus miembros se ganaban la vida en lavanderías a mano, restaurantes, servicio doméstico, manufactura de puros y zapatos, agricultura y otros servicios menores (Chan, 1986; Saxton, 1971; Zhou, 1992). Gradualmente, empero, un denso entrelazamiento de redes de personas del mismo grupo étnico y de la vida de las asociaciones surgió en los enclaves étnicos segregados, preocupado por la autosuficiencia, el autogobierno y la defensa en contra de la hostilidad del exterior. Dominaron tres tipos principales de organizaciones en los antiguos barrios chinos: asociaciones de familia/clan, asociaciones distritales y asociaciones de comerciantes, conocidas también como tongs (Dillon, 1962). Todas estas organizaciones surgieron por iniciativa de los propios inmigrantes, con escasa participación del Estado chino.

Las asociaciones de familia/clan se basaban en una combinación de nombres comunes o parentesco, la ascendencia ancestral y las aldeas de origen. Las asociaciones distritales estaban organizadas en torno a un dialecto en común o un lugar de nacimiento en común, de manera similar a las asociaciones de oriundos de los mexicanos. Tanto las asociaciones de familias como las distritales funcionaban como las familias chinas ampliadas tradicionales. Las tongs eran asociaciones de comerciantes de ayuda mutua, muchas de las cuales operaban como «hermandades» o sociedades secretas. Las tongs contaban con una membresía más variada e incluso con una fuerza de seguridad armada. Por medio de lenguajes secretos y de rituales religiosos o folk, las tongs consolidaron la solidaridad mutua y eventualmente dominaron la vida económica de los antiguos barrios chinos (Chin, 2000; Kwong, 1987). Entre otros ejemplos se incluyen las asociaciones Suey Sing, la asociación de comerciantes chinos On Leong y la asociación Hip Sing. Las organizaciones tradicionales establecieron profundas raíces al ser propietarias y reclamar el control territorial dentro del enclave. En muchos de los actuales barrios 
chinos, su presencia sigue siendo indiscutible, sus edificios marcados con el nombre de la organización y con la bandera ondeante de República de China (Taiwán) o de la República Popular China (RPC).

La vida organizacional de los antiguos barrios chinos culminó con la creación de las asociaciones chinas consolidadas de benevolencia (Chinese Consolidated Benevolent Associations [ссва]) entre mediados y fines del siglo XIX. Las asociaciones funcionaban como federaciones amplias, reuniendo a las organizaciones de familias, distritales y de comerciantes y actuaban como un gobierno de facto de la comunidad étnica (Kuo, 1977). Cada uno de los barrios chinos contaba con su propia сСвА, cuyas funciones incluían mediar en los conflictos internos, vigilar el comportamiento de los miembros de la comunidad y representar sus intereses ante el mundo exterior. La ссвA de San Francisco, fundada en 1854, estaba compuesta por las siete asociaciones distritales de mayor tamaño. La ссвA de Nueva York fue fundada en 1883 y reunió en una federación hasta 60 organizaciones; su contraparte en Los Ángeles fue establecida en 1889, reuniendo a 27 organizaciones. Muchas de estas federaciones celebraron su centenario en años recientes.

Debido a que la legislación opuesta a la inmigración china en gran medida prohibía la migración femenina, con lo que se inhibía la formación de familias en Estados Unidos, los inmigrantes chinos siguieron fuertemente orientados hacia el retorno. A pesar de sus circunstancias económicas precarias, enviaban dinero a sus lugares de origen con regularidad para sostener a progenitores, esposas e hijos y aportaban a sus aldeas de origen por medio de las organizaciones familiares o distritales. Los comerciantes chinos más exitosos viajaban entre un punto y otro, construyendo casas altamente engalanadas en sus aldeas de origen e invertían en tierras y negocios ahí mismo. Los lazos transnacionales eran pues bastante comunes al principio del siglo $\mathrm{xx}$, contradiciendo la imagen de las comunidades inmigrantes aisladas. Siguiendo las mismas líneas, las ссвAs y las asociaciones familiares o distritales de mayor tamaño, además de las tongs, comenzaron a participar en la vida política de China, más notablemente en la recolección de fondos para apoyar 
la revolución que derrocó a la última dinastía imperial de China, la Qing, en 1911. Esta revolución fue encabezada por el padre fundador de la República de China, Sun Yat-sen (1866-1925), un médico que emigró a Hawai cuando era adolescente, abandonó su carrera profesional y fundó la Hsing Chung Hui (Sociedad Revive China) en Honolulu como la base en ultramar de su movimiento nacionalista (Lai, 2004). Sun alguna vez llamó a los chinos en el extranjero «la madre de la revolución» para reconocer sus contribuciones.

\section{El DESARROLLO \\ ORGANIZACIONAL CONTEMPORÁNEO}

La población china de Estados Unidos decayó a cerca de 85 mil en los años veinte y se mantuvo alrededor de los 100 mil durante décadas hasta que dos acontecimientos trajeron consigo un marcado incremento. El primero fue la aprobación del decreto de inmigración a Estados Unidos de 1965 (US Immigration $A c t$ ), que reabrió la puerta a la inmigración asiática sobre el fundamento de la reunificación de las familias y la calificación ocupacional; el segundo fue el final de la Revolución Cultural en China y la normalización de las relaciones diplomáticas entre China y Estados Unidos a fines de los años setenta. A raíz de estos desarrollos resurgió el flujo de inmigrantes provenientes de China y creció exponencialmente durante las siguientes tres décadas. Se trató, empero, de un movimiento muy diferente respecto a la migración de fuerza de trabajo de un siglo antes (Chan, 1986). Aun cuando durante este periodo se incrementó la inmigración clandestina, principalmente desde Fujian, para alimentar las economías de los crecientes barrios chinos, la mayor parte de la nueva inmigración estuvo compuesta por profesionales y sus familias. La mayoría de los inmigrantes chinos que ya estaba en América tenía parientes cercanos en China. La nueva política no sólo permitía la migración de los progenitores, cónyuges e hijos, sino que también abrió nuevos canales para la migración familiar en cadena. Mientras tanto, el flujo chino asumió la forma de una «fuga de cerebros» 
que crecía a ritmo estable, inicialmente desde China durante fines de la década de 1940, luego desde Taiwán a fines de los años sesenta y más recientemente desde la República Popular (Portes y Rumbaut, 2006; Zhou, 2009).

La inmigración de chinos altamente calificados se dio en tres oleadas. La primera comprendió a unos cuantos miles de estudiantes y académicos de intercambio que estudiaron en Estados Unidos durante el periodo posterior a la segunda guerra mundial. Tras la derrota del gobierno nacionalista en 1949, Estados Unidos cortó los lazos diplomáticos con el nuevo gobierno continental, la República Popular China, y concedió la residencia permanente a todos los estudiantes y académicos chinos que ya estuvieran en Estados Unidos. La segunda oleada ocurrió entre los años sesenta y ochenta, cuando el gobierno nacionalista en Taiwán permitió y estimuló que miles de estudiantes acudieran a las universidades estadounidenses. La mayor parte de estos estudiantes decidió permanecer y desarrollar sus carreras en Estados Unidos. El tercer grupo de estudiantes y científicos chinos comenzó a llegar en los años ochenta, a raíz de un cambio radical en la política oficial china, tras el final de la Revolución Cultural.

China envió a más de 755 mil estudiantes al extranjero entre 1978 y 2008, la mitad de ellos hacia Estados Unidos. Menos de 15\% regresó. Las protestas en la Plaza Tiananmen en 1989 estimularon al Congreso de Estados Unidos a permitir que unos 60 mil estudiantes chinos y sus familias que ya estaban en Estados Unidos permanecieran de forma permanente. La aprobación de la legislación de $\mathrm{H}-1 \mathrm{~B}$ en los años noventa que facilitaba la contratación de técnicos y profesionales altamente calificados de parte de las corporaciones estadounidenses aceleró aun más el flujo hacia Estados Unidos. En 2002, por ejemplo, cerca de 19 mil visas H-1B se concedieron a graduados universitarios chinos; se unieron a otros 18 mil profesionales y trabajadores altamente calificados que fueron admitidos con residencia permanente (Portes y Rumbaut, 2006: 80).

A diferencia de los inmigrantes chinos de épocas anteriores que provenían de antecedentes socioeconómicos bajos y de orígenes rurales y que eran 
segregados en los barrios chinos, los inmigrantes chinos contemporáneos son muy diferentes tanto en su estatus socioeconómico como en sus lugares de origen y establecimiento. Su vida organizacional difiere también de la que llevaban sus predecesores. Desde los años setenta hubo incluso un aumento de nuevas organizaciones de inmigrantes chinos, muchas de ellas establecidas fuera de los barrios chinos. Aunque el gobierno chino se ha involucrado cada vez más en el campo transnacional, la gran mayoría de las organizaciones existentes ha sido creada por los propios migrantes.

La tabla 3 presenta el inventario de las organizaciones chinas compilado por el equipo de investigación de Princeton durante los seis meses de trabajo de campo en 2009-2010 en Los Ángeles, San Francisco y Nueva York. La generación de este registro se facilitó gracias a los directorios telefónicos en idioma chino en las tres ciudades y por la cooperación de los funcionarios consulares chinos. Aun así, el inventario no es de ninguna manera exhaustivo. Los funcionarios chinos estiman que las organizaciones étnicas chinas tan sólo en el sur de California alcanzan más de dos mil. Como una reflexión parcial sobre esta tendencia, las páginas amarillas para el consumidor chino en 2010 en el sur de California sumaban 2800 páginas.

A pesar de esta limitación, la lista en la tabla 3 capta la diversidad de las organizaciones de inmigrantes chinos, incluyendo a las de mayor tamaño y estabilidad. Como en el caso de las organizaciones latinoamericanas en la tabla 1, la clasificación de las organizaciones se basa en sus propias definiciones más que en una tipología a priori. A partir de esta lista de más de 1300 organizaciones, 55 de las más conocidas y mejor establecidas fueron seleccionadas para su estudio bajo la suposición de que eran las que más capacidad tendrían de participar en actividades transnacionales de importancia. Los líderes de estos grupos también fueron vistos como los mejor informados acerca de otras asociaciones en sus comunidades y, por tanto, los más calificados para reportar acerca del carácter de sus respectivos campos organizacionales. Fueron entrevistados cara a cara o por teléfono. 
TABLA 3

Cantidad y distribución porcentual de las organizaciones de inmigrantes chinos en Los Ángeles, San Francisco y Nueva York, 2010.

\begin{tabular}{|c|c|c|}
\hline Tipo & Número & Porcentaje \\
\hline Organización cívica & 130 & 9.5 \\
\hline Organización cultural & 53 & 3.9 \\
\hline Asuntos de salud & 12 & 0.9 \\
\hline Música/artes & 48 & 3.5 \\
\hline Deportes & 19 & 1.4 \\
\hline Federación & 4 & \\
\hline Organización única & 15 & \\
\hline Agencia de servicio social & 38 & 2.8 \\
\hline Política & 83 & 6.1 \\
\hline Federación & 4 & \\
\hline Organización única & 79 & \\
\hline Religiosa & 63 & 4.6 \\
\hline Federación & 2 & \\
\hline Organización única & 61 & \\
\hline Exalumnos & 142 & 10.4 \\
\hline Federación & 3 & \\
\hline Universidad & 111 & \\
\hline Educ. media & 28 & \\
\hline Educativa & 17 & 1.2 \\
\hline Federación & 2 & \\
\hline Organización única & 15 & \\
\hline Económica & 74 & 5.4 \\
\hline Federación & 22 & \\
\hline Organización única & 52 & \\
\hline Profesional & 146 & 10.6 \\
\hline Federación & 3 & \\
\hline Organización única & 143 & \\
\hline Oriundos (hometown) & 381 & 27.8 \\
\hline Federación & 43 & \\
\hline Asociación de clan/familias & 102 & \\
\hline Asociación de aldea & 44 & \\
\hline
\end{tabular}


Asociación distrital

Asociación provincial

Hermandad de comerciantes (tong)

Total 1
127

65

165

371
12.0

100.0

Fuente: Comparative Immigrant Organización Project (cIop) (compilado a partir de búsquedas en directorios telefónicos, boletines de las organizaciones, lista en el consulado e Internet).

La tabla 3 muestra que las organizaciones tradicionales, como las asociaciones familiares y distritales y las tongs, continúan dominando en las comunidades de inmigrantes chinos. En conjunto representan $40 \%$ del total. Junto a ellas, han crecido rápidamente formas más modernas de organización. En particular, las organizaciones educativas, de exalumnos y profesionales representan ahora $22 \%$ del total. Las asociaciones distritales también se han modernizado, muchas de ellas expandiéndose más allá del clan y la aldea y engloban regiones más amplias e incluso provincias. También se han hecho más transnacionales al tener lazos más estrechos con los funcionarios locales y provinciales en sus lugares de origen; muchas han sido creadas expresamente para este propósito.

Las organizaciones profesionales chinas de carácter formal en Estados Unidos están registradas como grupos sin fines de lucro. Están bien representadas en campos como la ciencia, la ingeniería, la medicina y las finanzas. La membresía va desde unas cuantas docenas hasta varios miles. Más de 90\% de estas organizaciones son transnacionales, conservando lazos con las agencias del gobierno chino en los ámbitos nacional, provincial y distrital. Regularmente, tienen congresos en Estados Unidos y China. Los ejemplos incluyen la Chinese Association for Science and Technology-USA (nacional, con 15 capítulos regionales), la Silicon Valley Chinese Engineers Association (con sede en California) y la Chinese Biopharmaceutical Association (con sede en Washington, DC).

Como en el caso de las organizaciones profesionales, existían pocas asociaciones de exalumnos en los barrios chinos tradicionales, pues la gran 
mayoría de sus habitantes carecía siquiera de educación secundaria. A diferencia de las organizaciones chinas tradicionales, las asociaciones de exalumnos están formadas con base en las universidades y los colleges y, en menor medida, las escuelas de educación media de las que se graduaron los inmigrantes en China. La principal misión de las asociaciones de exalumnos es formar redes e intercambiar información entre los miembros. Sus actividades transnacionales están orientadas principalmente a apoyar a sus respectivos graduados. Los miembros de estas organizaciones por lo común también son miembros de asociaciones profesionales y cívicas cuyo abanico de actividades es mucho más amplio. A diferencia de las tongs de los antiguos barrios chinos, las nuevas organizaciones económicas dependen fuertemente de las redes transnacionales para operar y ampliar sus negocios.

Estas organizaciones empresariales, por lo general, expresan un marcado deseo por integrarse en la economía y el sistema político estadounidense. Se ven a sí mismas como agentes de cambio, ubicadas al frente de la economía global y haciendo las veces de «Puerta a la Cuenca del Pacífico». Estas organizaciones combinan su postura a favor de la integración con la promoción de la solidaridad étnica entre los chinos, tanto con propósitos económicos como para la subsistencia cultural (Zhou, 2010).

\section{EL TRANSNACIONALISMO CHINO EN MOVIMIENTO}

En 1978 la oficina china de asuntos exteriores del Consejo de Estado de China (Qiao-ban nacional) y las oficinas similares en provincias y ciudades seleccionadas fueron reactivadas tras haber permanecido inertes en los años de la Revolución Cultural. Las políticas del Partido Comunista Chino cambiaron drásticamente, de ver a sus expatriados como potenciales espías y traidores, a recibirlos como «sostenes, pioneros y promotores» de la reforma económica de China. En mayo de 1989, el Consejo de Estado reiteró la im- 
portante papel de los chinos en el extranjero para poner en práctica la nueva política china de puertas abiertas al invertir en China y al transferir tecnología. ${ }^{4}$ La política hacia los estudiantes en el extranjero, que inicialmente enfatizaba el retorno, también se relajó en los años noventa para reconocer que regresar a China «no es la única forma de servir al país». ${ }^{5}$

Paralelamente a estos desarrollos se dio la reactivación de los diversos niveles de la Federación de Chinos de Retorno de Ultramar (Qiao-lian). La Qiao-lian fue establecida por el Partido Comunista a principios de la década de los cincuenta con funciones paralelas a las de Qiao-ban. Tanto Qiao-ban como Qiao-lian cuentan con oficinas en los ámbitos nacional, provincial, distrital y de las ciudades, atendidas por funcionarios pagados cuyo rol consiste en mantener un contacto regular con las comunidades inmigrantes en todo el mundo y promover sus actividades transnacionales. Esta compleja burocracia, que se apoya en los pilares gemelos del Estado y el Partido, intersecta la amplia red de organizaciones de inmigrantes chinos creando una fuerte sinergia. Las contribuciones de parte de las organizaciones de oriundos y otras asociaciones cívicas, profesionales y de exalumnos han financiado desde carreteras y escuelas hasta universidades enteras. Por ejemplo, la Universidad de Wuyi en Jiangmen, provincia de Guandong, fue creada con las contribuciones de los expatriados en Estados Unidos, Canadá y el sureste de Asia. Uno de sus principales edificios, llamado «Diez amigos» (Ten Friends), que alberga un amplio auditorio y otras instalaciones para congresos, fue pagado (como su nombre lo indica) por diez empresarios chinos ricos en ultramar. ${ }^{6}$

/4/ Véase 〈http://qwgzyj.gqb.gov.cn/qwhg/146/1346.shtml>, consultada el 22 de enero de 2010.

15/ Véase http://202.205.177.9/edoas/en/level3.jsp?tablename=1242702622613408\&in foid=1253167200778185 , consultada el 22 de enero de 2010.

${ }^{16 /}$ La Universidad de Wuyi realizó recientemente un simposio internacional con el tema Immigration and the Contributions of Overseas Chinese to Regional Development (septiembre 2010). El simposio se realizó en el edificio Ten Friends. 
La figura 2 representa la estructura del gobierno chino y de las agencias del partido que tratan con la población china en el extranjero. La figura 3 ofrece ejemplos seleccionados de actividades en el campo transnacional chino.

FIGURA 2

Estructura de las organizaciones de asuntos extranjeros chinos de la República Popular China (RPC) y del comité central del Partido Comunista Chino (PCC).

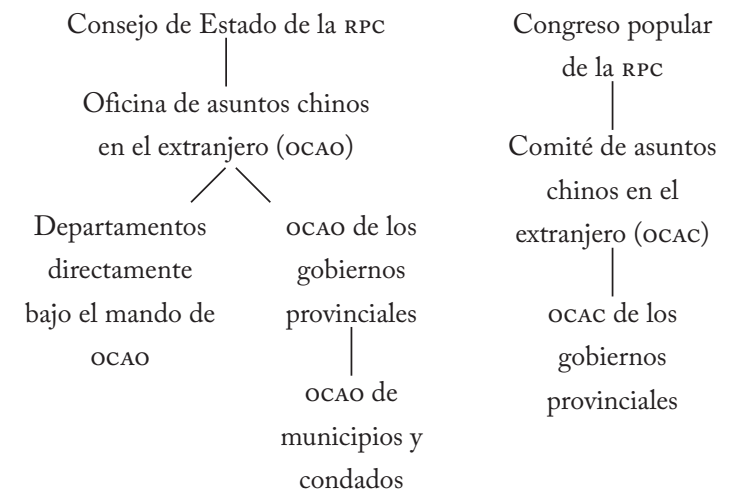

Fuente: elaboración propia.

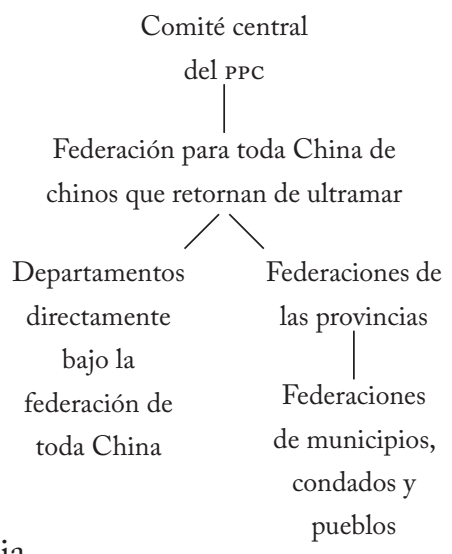

pueblos

La inversión china en el extranjero es responsable del rápido desarrollo económico de las zonas costeras, en especial en Shanghai y otras ciudades de menor tamaño en el delta del río Yangtze y en Guangzhou y otras ciudades pequeñas en el delta del río Perla. Por medio de sus agencias en diversos niveles, el Estado y el partido han cultivado asiduamente estos desarrollos al recibir y cumplimentar a los líderes de las organizaciones de expatriados y a los inversionistas de importancia, financiando congresos profesionales y empresariales y como anfitriones de festivales y celebraciones tanto en China como a través de su red de consulados en Estados Unidos y en otras partes del mundo. Algunos ejemplos de estas actividades incluyen los campamentos de verano y de invierno para los jóvenes chinos en el extranjero, organizados por Qiao-ban en varios niveles y los programas de instrucción en idioma 
chino, definidos por el gobierno como «un empleo altamente significativo, estratégico» y organizado por el Consejo de Idioma Chino (Chinese Language Council) a través de una red de Institutos Confucio (ICs) en el extranjero. En junio de 2010 había 64 Ics en 37 estados de Estados Unidos tras haberse establecido el primero en 2005 (Chiu, 2010).

\section{FIGURA 3}

Conexiones transnacionales de las organizaciones de inmigrantes chinos: ejemplos seleccionados.

\begin{tabular}{|c|c|c|}
\hline Estados Unidos & & China \\
\hline $\begin{array}{l}\text { Programas de formación para líderes de } \\
\text { comunidades de inmigrantes chinos } \\
\text { en el extranjero }\end{array}$ & \multirow{3}{*}{4} & \multirow{3}{*}{ Qiao-ban y Qiao-lian nacionales } \\
\hline $\begin{array}{l}\text { Asociación mundial de empresarios chinos } \\
\text { Mantenimiento del idioma por medio de } \\
64 \text { Institutos Confucio }\end{array}$ & & \\
\hline $\begin{array}{l}\text { Campamentos de búsqueda de raíces } \\
\text { chinas para la juventud china } \\
\text { en el extranjero }\end{array}$ & & \\
\hline Congresos profesionales y empresariales & \multirow[t]{2}{*}{$\leftarrow$} & $\begin{array}{l}\text { Qiao-ban y Qiao-lian provinciales } \\
\text { (Guangdong, Fujian) }\end{array}$ \\
\hline Festivales provinciales y locales & & \\
\hline ссва de Nueva York & $>$ & $\begin{array}{l}\text { Donación de } 90 \text { mil dólares para las } \\
\text { víctimas del tifón de } 2009 \text { en China }\end{array}$ \\
\hline $\begin{array}{l}\text { ссва de San Francisco y } \\
\text { asociación Suey Sing }\end{array}$ & & $\begin{array}{l}\text { Organización de las ceremonias de } \\
\text { bienvenida de la antorcha olímpica en } \\
\text { Beijing } 2008\end{array}$ \\
\hline $\begin{array}{l}\text { Asociación china para la ciencia y } \\
\text { la tecnología (CAST-USA) }\end{array}$ & $\rightarrow$ & $\begin{array}{l}\text { Co-patrocinio del Congreso } \\
\text { Internacional Wuhan sobre el } \\
\text { ambiente en } 2009\end{array}$ \\
\hline Asociación de aldea Baisha & $\rightarrow$ & $\begin{array}{l}\text { Donativos de boda (xi-juan) y } \\
\text { donativos de felicidad (le-juan) para } \\
\text { mejoras en infraestructura en Baisha } \\
\text { (provincia de Fujian) }\end{array}$ \\
\hline
\end{tabular}

Nota: Véase el texto para la explicación de los nombres de agencias y asociaciones. 
Los funcionarios chinos están conscientes de que una presencia excesivamente visible en Estados Unidos puede desencadenar reacciones desfavorables de parte del público estadounidense. Por tal razón, limitan sus actividades principalmente a los barrios chinos y a los consulados, mientras que buscan cultivar a los funcionarios estadounidenses en nombre de la cooperación chino-estadounidense (Zhou, 2010). Los funcionarios de Qiao-ban y Qiao-lian visitan Estados Unidos con regularidad, y son recibidos por los líderes de las organizaciones chinas más importantes en varias ciudades. El primero de octubre (el día nacional de la RPC), el gobierno ofrece suntuosas fiestas en sus cuatro consulados generales (Nueva York, San Francisco, Los Ángeles y Houston) a las que están invitados los líderes de todas las organizaciones de inmigrantes chinos de importancia, así como empresarios y prominentes funcionarios públicos estadounidenses. El sostenido crecimiento económico de China durante las décadas recientes ha hecho que la meta de promover mayores inversiones de los chinos en el extranjero sea menos importante que en el pasado. En el siglo xxi, la política del gobierno se ha reorientado a fortalecer las redes con las organizaciones de inmigrantes, fomentando los intercambios tecnológicos y culturales y apoyando el desarrollo de las comunidades chinas en el extranjero como una forma de promover la «buena imagen» y el creciente estatus de China. ${ }^{7}$

\section{Comparación de las organizaciones \\ TRANSNACIONALES MEXICANAS Y CHINAS}

La tabla 4 presenta una síntesis de las características de México y China y sus respectivas poblaciones de inmigrantes en Estados Unidos como telón de fondo para la siguiente discusión. Mientras que, como vimos antes, hay mu-

${ }^{17 /}$ Entrevista con el líder de la Qiao-ban de Guangdong, en verano de 2009.

1384 MIGRACIÓN Y DESARROLLO, VOL. 11, NÚM. 20, PRIMER SEMESTRE DE 2013 
chas similitudes entre los países, las diferencias son notables. Ambos gobiernos cambiaron sus actitudes hacia sus expatriados, de considerarlos con indiferencia u hostilidad, a cultivar activamente su lealtad. El cambio se dio primero en China, con el fin de la Revolución Cultural y la activación de las Qiao-ban y Qiao-lian nacionales, provinciales y locales. En México, se dio a principios de los años noventa en el sexenio del presidente Vicente Fox y culminó con la creación del Instituto para los Mexicanos en el Extranjero y su consejo consultivo, electo por primera vez en 2002 (Escobar, 2007; Iskander, 2010).

No han sido las acciones de ninguno de los gobiernos las que generaron el campo transnacional. Éste se desarrolló, en múltiples formas, como consecuencia de la iniciativa y los esfuerzos de los propios inmigrantes. Sin embargo, las actividades que han puesto en marcha los gobiernos han fortalecido en gran medida estas interacciones y ampliado el impacto sobre el desarrollo del transnacionalismo hacia nuevas direcciones. Ambos gobiernos se han beneficiado de la fuerte lealtad de sus expatriados hacia sus lugares de origen, la que ha dado lugar a cientos de asociaciones de familias y clanes y de asociaciones distritales entre los chinos y de cantidades similares de comités de oriundos entre los mexicanos. Como escribe Escobar (2007: 257): «Una de las principales características de las organizaciones mexicanas en Estados Unidos es su importante base rural y eso hace que el comité de oriundos sea la forma predominante de asociación. Estos comités reproducen, en una forma o en otra, las estructuras locales de los lugares de origen y sus modos de operación».

En los niveles superiores de organización, por otra parte, existe una notable diferencia entre los dos grupos, marcada por la creación de instituciones de autogobierno de parte de los inmigrantes chinos - las tongs- y las organizaciones de beneficencia más amplias (сСвAs) y, subsecuentemente, la proliferación de asociaciones modernas para profesionales, cívicas y de exalumnos. Existe muy poca actividad de este tipo entre los expatriados mexicanos, a pesar de que su presencia en Estados Unidos es mucho más numerosa. Las federaciones de comités de oriundos representan formas asociativas superiores, pero muchas fueron creadas a instancias y con el apoyo de los estados mexicanos de 
origen (Goldring, 2002; Iskander, 2010). Estas federaciones tampoco proveen forma alguna de autogobierno pues son esencialmente vehículos para el diálogo y para la canalización de las demandas hacia las autoridades mexicanas. Aunque existen organizaciones profesionales y otras organizaciones modernas entre los inmigrantes mexicanos (véase tabla 1), carecen de la profundidad y las cantidades que se dan entre los chinos. Este contraste refleja esencialmente los muy diferentes perfiles en cuanto a capital humano de las dos comunidades de expatriados como se muestra en la tabla 4.

TABLA 4

Características de las poblaciones de China y México y sus comunidades de inmigrantes en Estados Unidos.

\begin{tabular}{|c|c|c|}
\hline & China & MÉXICO \\
\hline \multicolumn{3}{|l|}{ PAís de oRigen } \\
\hline Población, 2010 (millones) & 1,336 & 114 \\
\hline Población urbana (porcentaje) & 47.0 & 78.0 \\
\hline Esperanza de vida al nacer (años) & 74.7 & 76.5 \\
\hline PIB per cápita, 2011 (dólares EUA) & 7,519 & 15,204 \\
\hline Índice Gini de inequidad, 2010 & 47. & 47. \\
\hline \multicolumn{3}{|l|}{ LOGRO EDUCATIVO } \\
\hline $\begin{array}{l}\text { Porcentaje de graduados de } \\
\text { universidad, adultos } 25-64\end{array}$ & 9.0 & 15.9 \\
\hline Porcentaje de graduados de secundaria & 14.0 & 19.3 \\
\hline $\begin{array}{l}\text { Tasa de desempleo, porcentaje de } \\
\text { la fuerza laboral civil (2010) }\end{array}$ & 4.1 & 5.4 \\
\hline $\begin{array}{l}\text { Participación en la fuerza de trabajo, } \\
\text { porcentaje de población adulta (2009) }\end{array}$ & 61.8 & 61.4 \\
\hline \multicolumn{3}{|l|}{ InMigrantes En Estados Unidos } \\
\hline Cantidad, 2009 (millones) & 2.2 & 11.4 \\
\hline Inmigrantes legales, 2010 & 70,863 & 139,120 \\
\hline $\begin{array}{l}\text { Porcentaje del total de } \\
\text { la inmigración legal a EUA, } 2010\end{array}$ & 6.8 & 13.3 \\
\hline Rango en la inmigración legal total, 2010 & 2 & 1 \\
\hline
\end{tabular}


Ocupaciones profesionales

especializadas, porcentaje

Graduados de universidad, porcentaje

Mediana del ingreso

del hogar, 2010 (dólares EUA)

Tasa de pobreza, 2010 (porcentaje)

Tipos de inmigración

Principales ciudades de destino
52.8

50.8

69,037

11.0

Principalmente legal, algunos ingresos no autorizados

Nueva York, San Francisco, Los Ángeles
15.5

39,115

29.0

Dividida aproximadamente igual entre inmigrantes legales y no autorizados Los Ángeles, Chicago, Houston

Fuente: us Bureau of the Census, 2009 y 2010 American Community Surveys. Office of Immigration Statistics, Department of Homeland Security, 2010 Annual Report. ciA, World Fact Books, «www.cia.gov/library/publications〉. OECD Observer, OECD in Figures 2009, Supplement \#1, «www.oecd. org/publishing». oEcD, «Country Statistical Profiles» (China y México), 2011, «ttp://stats.oecd.org/». Jeffrey S. Passel, «The economic downturn and immigration trends», Washington Dc, Pew Hispanic Center Report, marzo de 2009.

De tal modo, el gobierno chino, en todos los niveles administrativos, está en mejor posición para interactuar y participar con sus expatriados dado que en gran medida son autosuficientes y gozan de un estatus legal y económico más seguro. Con el objeto de interactuar con sus inmigrantes en Estados Unidos, el gobierno mexicano ha tenido que invertir más recursos y ser más proactivo. Este esfuerzo ha asumido múltiples formas, entre ellas la creación del Programa 3x1 para estimular las contribuciones filantrópicas de los migrantes; el financiamiento de más de cien plazas comunitarias en ciudades de Estados Unidos donde se imparten cursos de idioma inglés y de idioma español y cursos de extensión de educación media para los migrantes y sus hijos, y la creación de la matricula consular para ofrecer a los inmigrantes no autorizados una forma de identificación. 
Ninguna de estas iniciativas tiene paralelo entre las asumidas por el gobierno chino, con excepción de la enseñanza del idioma a través de los Institutos Confucio. Ello es así porque la comunidad china en Estados Unidos cuenta con más recursos para ofrecer estos servicios, siendo que por lo general tienen alta escolaridad, más ingresos y con un estatus legal seguro. Incluso la instrucción del idioma es diferente porque las plazas están ocupadas en gran medida en enseñar habilidades básicas de escritura y lectura para migrantes de escasa escolaridad, mientras que la misión de los Institutos Confucio es propagar el idioma chino y el conocimiento cultural entre los chinos y los estadounidenses por igual y entre los miembros de otros grupos de origen nacional. Las actividades del gobierno chino están centradas, pues, en promover la continuada lealtad de sus expatriados y reforzar y celebrar su cultura como una forma de mejorar la imagen de China en el exterior (Zhou, 2010).

Esta meta puede lograrse a un costo relativamente modesto por medio de ceremonias de reconocimiento en honor de científicos y empresarios prominentes, la organización de congresos, festivales y banquetes, y el patrocinio de grupos de artistas chinos que viajen al extranjero para presentarse ante audiencias de expatriados. Debido a que ni la comunidad de inmigrantes ni el gobierno chino requieren con urgencia de transferencias económicas, el honor y el reconocimiento del estatus se han convertido gradualmente en la principal «divisa» de sus intercambios transnacionales.

En ambos países la relación entre el Estado y la comunidad de expatriados se facilita por los intereses comunes que incluyen las consideraciones materiales y de estatus. Para los funcionarios de gobierno los inmigrantes representan una importante fuente de contribuciones económicas a través de las remesas e inversiones individuales y de la filantropía organizada. También son el «rostro de la nación» en el extranjero y, como tal, ayudan a definir la imagen y la posición relativa del país en el sistema global. Para los inmigrantes y, especialmente para sus líderes, el reconocimiento de parte de las autoridades del país de origen valida la legitimidad de sus organizaciones y su propio estatus. De este modo los migrantes con medios modestos y de poca importancia en 
sus localidades de origen, antes de salir al extranjero, pueden convertirse en figuras respetadas y prominentes. En este sentido la relación representa una situación "ganar-ganar» que estimula el surgimiento de nuevas organizaciones transnacionales y la consolidación de aquéllas que ya existen.

\section{Conclusión}

E1 intenso tráfico transnacional en el que participan las organizaciones de inmigrantes y los gobiernos de los países de origen ha hecho surgir preocupaciones entre las autoridades y algunos comentaristas públicos en Estados Unidos por razones que ya se mencionaron previamente: la probable desaceleración del proceso de asimilación a la sociedad estadounidense y los posibles huecos en la seguridad nacional. Estas preocupaciones se ven negadas, empero, por la fuerte postura a favor de la integración de las organizaciones de inmigrantes y el hecho de que los consulados y funcionarios de los países de origen han buscado extinguir cualquier sentimiento o acciones antiestadounidenses o aislacionistas entre sus expatriados. Las agencias de los gobiernos chino y mexicano, en contacto con sus nacionales en el extranjero, ven a las actividades transnacionales como un beneficio para el país de origen, pero no como una barrera a la integración en el país receptor. Los líderes de las organizaciones de inmigrantes entrevistados durante las distintas etapas de nuestro estudio apoyaron consistentemente la adquisición de la ciudadanía estadounidense y la participación en la vida cívica estadounidense y no veían contradicción alguna entre esas actividades y mantener un diálogo continuado y unas actividades filantrópicas en el país de origen (Portes, Escobar y Arana, 2008; Zhou, 2010).

Tanto México como China están de acuerdo con Estados Unidos en su oposición a las asociaciones fundamentalistas violentas. Quizá como consecuencia, las autoridades estadounidenses han adoptado una postura benigna hacia sus actividades transnacionales y, eventualmente, las han apoyado. 
Ejemplo de ello son la cooperación del IME con las autoridades municipales en Estados Unidos en la provisión de servicios de salud y de instrucción en idiomas a los inmigrantes y la presencia de los funcionarios estadounidenses en los acontecimientos y festividades comunitarias con patrocinio de los consulados mexicano y chino en Estados Unidos. Debido a que nuestro estudio se limita al caso de Estados Unidos, estas conclusiones no pueden generalizarse a otras sociedades receptoras de migrantes. Sigue abierta la pregunta de si este mismo patrón se presenta en los países del oeste de Europa, por ejemplo (Lacroix, 2005; Baübock, 2003).

La literatura tradicional sobre el desarrollo nacional prestaba escasa atención a la migración internacional. Cuando lo hacía, tendía a ser tal que esos flujos constituían un síntoma de subdesarrollo, o que estos flujos contribuían aun más a esa condición al dejar vacías a regiones enteras y sacar el escaso talento atraído por una remuneración más alta en el extranjero (Frank, 1967; Cheng y Bonacich, 1984; Díaz-Briquets y Weintraub, 1991). El volumen creciente de las remesas de los migrantes ha cambiado estas percepciones al enfatizar el importante papel de las transferencias, tanto para paliar la pobreza nacional como para mejorar los saldos de divisas en la balanza comercial. Las organizaciones internacionales, como el Banco Mundial, han apoyado esta visión viendo a las remesas de los migrantes como una inesperada "costura áurea», potencialmente capaz de financiar proyectos de desarrollo en vez de la escasa asistencia internacional.

En contraste, los académicos de los países de origen de los migrantes han criticado recientemente esta perspectiva al enfatizar los aspectos negativos de la emigración. En su visión, la migración no sólo tiene el potencial para despoblar regiones enteras, sino que el volumen de las remesas que envían los expatriados ofrece una válvula de escape a la pobreza en el país, permitiendo a los gobiernos y elites evitar la responsabilidad de paliarla. Según esta perspectiva, la emigración sirve para consolidar la inequidad y el estancamiento económico en vez de ayudar a superarlos (Delgado Wise y Cypher, 2007; Castles, 2010). 
Una perspectiva más refinada define los costos y beneficios para el desarrollo de la migración internacional como dependientes de varios factores, incluyendo la capacidad institucional de los gobiernos de los países de origen y el tipo y duración de la migración. La emigración permanente, por lo general, tiene consecuencias negativas ya que puede llevar a un decrecimiento poblacional y a una estructura de edad distorsionada en las áreas de origen y privar a los países pobres de un capital humano ya escaso. Los migrantes permanentes tienden también a llevarse a sus familias con ellos, retirando el incentivo para continuar enviando remesas a sus lugares de origen. La migración circular puede tener consecuencias benéficas debido a la transferencia de recursos monetarios, de información y de know-how que los migrantes de retorno pueden llevar a sus lugares de origen. En especial en los casos en que estas contribuciones se combinan con una postura proactiva de los gobiernos de los países de origen, en capacidad de apoyar las iniciativas de los migrantes y de canalizarlas adecuadamente (Massey, Durand y Malone, 2002; Saxenian, 2002). La dificultad consiste en que muchos migrantes se resisten al retorno debido a la escasez de oportunidades en su lugar de origen y la experiencia o al menos los prospectos de una vida mejor en el extranjero. Esto explica, entre otras cosas, porqué ha sido tan difícil para los gobiernos de los países de origen el revertir la «fuga de cerebros» a través de persuadir a los profesionales expatriados para que regresen (Díaz-Briquets y Weintraub, 1991; Cheng y Bonacich, 1984).

Entra en escena el transnacionalismo. La creación de organizaciones transnacionales significa que los migrantes, incluso cuando se han establecido permanentemente en el extranjero, no tienen que abandonar las conexiones con sus países de origen (Baübock, 2003). Además, la evidencia empírica que hemos presentado nosotros y otros más indica que, mientras más establecidos y más seguros en términos financieros y legales están los migrantes, más tienden a participar en actividades transnacionales, incluyendo los viajes de ida y vuelta entre los países de expatriación y los países de origen. Si el tráfico alcanza volumen suficiente, tiene el potencial de convertir a las migraciones permanentes en circulares. Es decir, el campo transnacional facilita 
que los expatriados establecidos regresen a sus lugares de origen con regularidad, realizar transferencias monetarias y de conocimiento y generalmente participar en la vida social de sus lugares de origen al mismo tiempo que siguen consolidando sus vidas en el extranjero. ${ }^{8}$

Los gobiernos alertas de los países de origen, entre ellos los de México y China, han hecho conciencia de este potencial y en gran medida han abandonado los intentos por atraer el regreso de sus profesionales, en vez de estimularlos (así como a sus migrantes con menor escolaridad) a que se involucren en el campo transnacional. Dado el tamaño de las comunidades de expatriados, el potencial para el desarrollo de estas actividades es significativo, como los muestran los cientos de proyectos de obras públicas financiados por las contribuciones de los migrantes; en el caso de China, lo demuestra el determinante papel de los inversionistas chinos de ultramar en el desarrollo de las regiones costeras del país (Leung, 2008). Queda claro que China cuenta con la ventaja en comparación con México a este respecto, debido a la composición socioeconómica más diversa de su población migrante, su mayor nivel de escolaridad y su fortaleza empresarial.

La investigación ha mostrado que el activismo transnacional es, en gran medida, un fenómeno asociado con una generación, ya que el proceso de asimilación inevitablemente lleva a los miembros de la segunda generación a prestar atención hacia el interior de su nuevo país (Konczal y Haller, 2008). No obstante, mientras dura, el activismo transnacional unifica a poblaciones dispersas en el planeta, apoya los proyectos de infraestructura y el avance tecnológico en los países más pobres y proporciona un fundamento para una comunicación más productiva entre los países de origen y de destino (Guarnizo, Portes y Haller, 2003; Vertovec, 2004, 2009).

${ }^{18 /}$ El trabajo reciente del Foro Global sobre Migración Internacional y Desarrollo ha enfatizado la creciente importancia de estas conexiones. El tema de la reunión del foro en 2011 fue «Taking Action on Migration and Development: Coherence, Capacity and Cooperation», «www.gfund.org».

146 MIGRACIÓN Y DESARROLLO, VOL. 11, NÚM. 20, PRIMER SEMESTRE DE 2013 
Concluimos que la teoría y la práctica del desarrollo no pueden seguir representando a la migración como simplemente un síntoma de subdesarro1lo, ni reducir su papel a las remesas individuales. Esta red cada vez más compleja de organizaciones transnacionales y sus crecientes interacciones con los gobiernos en todos los niveles obligan a los académicos y a los diseñadores de políticas, por igual, a incorporar las comunidades de expatriados en cualquier análisis definitivo de los prospectos para el desarrollo de los países de origen. México y China, cada uno a su manera, han preparado el camino demostrando cómo puede aprovecharse ese potencial. La gran cantidad de países de origen menos desarrollados puede aprender de estas experiencias al buscar interactuar con sus propias comunidades en el extranjero. Las teorías académicas del desarrollo todavía no han alcanzado a estas realidades, dejando de lado con ello una importante dinámica de desarrollo en un mundo cada vez más globalizado.

\section{REFERENCIAS}

Ansley, Fran y Jon Shefner (2009), Global Connections, Global Receptions: New Latino Immigration to the Southeastern United States, Knoxville, University of Tennessee Press.

Arias, Patricia (2008), «Mexico's rural agenda: themes and dilemmas», lecture delivered at the Center for Migration and Development, Princeton University, abril.

ArizA, Marina y Alejandro Portes (2007), «La migración internacional de mexicanos: escenarios y desafíos de cara a un nuevo siglo» en Marina Ariza y Alejandro Portes (editores), El País Transnacional, México, IIs, UNAM, pp. 1-51.

Banco Mundial (2010), «Migration and development brief, 12», Migration and Remittances Team, Development Prospects Group, 23 abril, http://remittancesgateway.org/index.php/factbook». 
Barrera, Mario (1980), Race and Class in the Southwest: A Theory of Racial Inequality, Notre Dame, Notre Dame University Press.

Вачвӧск, Rainer (2003), «Toward a political theory of migrant transnationalism», International Migration Review, volumen 37, número 3.

BorJas, George (1990), Friends or Strangers: The Impact of Immigrants on the U.S. Economy, Nueva York, Basic Books.

Castles, Stephen (2010), «Understanding global migration: A social transformation perspective», Journal of Ethnic and Migration Studies, 36, diciembre, 1565-1586.

Chan, Sucheng (1986), This Bitter Sweet Soil: The Chinese in California Agriculture, 1860-1910, Berkeley, University of California Press.

Cheng, Lucie y Edna Bonacich (1984), Labor Migration Under Capitalism, Berkeley, University of California Press.

Chin, Ko-lin (2000), Smuggled Chinese: Clandestine Immigration to the United States, Filadelfia, Temple University Press.

Chiu, Michael (2010), «Map of Confucius Institutes in the U.s.», Us-China Today, University of Southern California, http://www.uschina.usc. edu/article@usct?map_of_confucius_institutes_in_the_u_s_14774. aspx>.

Cornelius, Wayne (1998), «The structural embeddedness of demand for Mexican immigrant labor: New evidence from California» en M. Suarez-Orozco (editor), Crossings: Mexican Immigration in Interdisciplinary Perspective, Cambridge, Center for Latin American Studies, Harvard University.

D’Aubeterre, Maria A. (2007), «Aquí respetamos a nuestros esposos: migración masculina y trabajo femenino en una Comunidad Nahua» en Marina Ariza y Alejandro Portes (editores), El Pais Transnacional, México, Instituto de Investigaciones Sociales, unAm.

De la Garza, Rodolfo y Miriam Hazan (2003), Looking Backward, Moving Forward: Mexican Organizations in the U.S. as Agents of Incorporation and Dissociation, Claremont, Tomas Rivera Policy Institute.

1484 MIGRACIÓN Y DESARROLLO, VOL. 11, NÚM. 20, PRIMER SEMESTRE DE 2013 
Delano, Alexander (2011), Mexico and its Diaspora in the United States, Nueva York, Cambridge University Press.

Delgado Wise, Raúl y Humberto Márquez Covarrubias (2006), The Reshaping of Mexican Labor Exports under NAFTA, Zacatecas, University of Zacatecas, International Network of Migration and Development.

Delgado Wise, Raúl y James M. Cypher (2007), «The strategic role of Mexican labor under NAFTA: Critical perspectives on current economic integration», Annals of the American Academy of Political and Social Science, volumen 610, número 3.

Diaz-Briquets, Sergio y Sidney Weintraub (1991), Migration, Remittances, and Small Business Development: Mexico and Caribbean Basin Countries, Boulder, Westview Press.

Dillon, Richard H. (1962), The Hatchet Men: The Story of the Tong Wars in San Francisco's Chinatown, Nueva York, Ballantine Books.

Escobar, Cristina (2007), «Migración y derechos ciudadanos: el caso mexicano» en Marina Ariza y Alejandro Portes (editores), El País Transnacional, México, iIs, unam, pp. 231-274.

(2010), «Colombian organizations and their relationships with home communities», paper presented at the Seminar on Immigrant Transnational Organizations and Development, Center for Migration and Development, Princeton University, abril.

Evans, Peter (2004), «Development as institutional change: The pitfalls of monocropping and the potentials of deliberation", Studies in Comparative International Development, volumen 38, número 4.

Frank, Andre Gunder (1967), Capitalism and Underdevelopment in Latin America, Nueva York, Monthly Review Press.

Freeman, Gary P. (2004), «Immigrant incorporation in Western democracies», International Migration Review, volumen 38, número 3.

Gammeltoft, P. (2002), «Remittances and other financial flows to developing countries», working paper prepared for the Center for Development Research, Copenhage, Dinamarca, marzo. 
García, Mario (1981), Desert Immigrants: The Mexicans of El Paso, 18801920, Nueva Haven, Yale University Press.

Glick-Schiller, Nina y Georges Fouron (1999), «Terrains of blood and nation: Haitian transnacional social fields», Ethnic and Racial Studies, volumen 22, número 3.

Global Migration Forum (2011), «Taking action on migration and development», Ginebra, Switzerland, «www.gfund.org».

Goldring, Luin (2002), «The Mexican state and transmigrant organizations: Negotiating the boundaries of membership and participation», Latin American Research Review, volumen 37, número 3.

Gonzalez Gutierrez, Carlos (2005), «Mexico's relation to its diaspora», keynote address to the Hispanic Summit of the Plains Conference, sponsored by the Office of Latin and Latino Affairs (ollas), University of Nebraska-Omaha, abril.

Guarnizo, Luis E. (2003), «The economics of transnational living», International Migration Review, volumen 37, número 3.

, Alejandro Portes y William Haller (2003), «Assimilation and transnationalism: determinants of transnational political action among contemporary immigrants», American Journal of Sociology, volumen 108, número 5.

Hoff, Karla y Joseph Stiglitz (2001), «Modern economic theory and development» en Gerald Meier y Joseph Stiglitz (editores), Frontiers of Development Economics, Nueva York, Oxford University Press.

Hollifield, James F. (2004), «The emerging migration state», International Migration Review, volumen 38, número 3.

Iranzo, Susana y C. Ma. Alyson (2006), «The effect of China on Mexico-u.s. trade: Undoing NAFTA?», Report, University of California, San Diego, ‘http://www.sandiego.edu/peacestudies/documents/tbi/iranzo_ma_ Tві.pdf.

Iskander, Natasha (2010), Creative State: Forty Years of Migration and Development Policy in Morocco and Mexico, Ithaca, Cornell University Press. 
ItZigsohn, José y Silvia G. Saucido (2002), «Immigrant incorporation and sociocultural transnationalism», International Migration Review, volumen 36, número 3.

Joffe-Block, Jude (2010), «Immigration viewed from the other side», Berkeley Review of Latin American Studies, primavera-verano.

KonczaL, Lisa y William J. Haller (2008), «Fit to miss, but matched to hatch: Success factors among the second generation's disadvantaged youth in South Floridan, The Annals of the American Academy of Political and Social Science, volumen 620, número 1.

Kuo, Chia-ling (1977), Social and Political Change in Nerw York's Chinatown: The Role of Voluntary Associations, Nueva York, Praeger Publishers.

Kwong, Peter (1987), The New Chinatown, Nueva York, Hill \& Wang. Lacroix, Thomas (2005), Les Reseaux Maroccains du Developpment, París, Presses de la Fondation Nationale de Sciences Politiques.

LaI, Him Mark (2004), Becoming Chinese American: A History of Communities and Institutions, Alta Mira Press.

Landolt, Patricia, Lilian Autler y Sonia Baires (1999), «From "hermano lejano" to "hermano mayor": The dialectics of Salvadoran transnationalism», Ethnic and Racial Studies, volumen 22, número 3.

Leung, Maggie (2008), «Homeward-bound investors: The role of overseas Chinese in China's economic development» en Ton van Naerssen, Ernst Spaan y Annelies Zoomers (editores), Global Migration and Development, Nueva York, Routledge.

Massey, Douglas S. (2007), «Borderline madness: America’s counterproductive immigration policy» en Carol M. Swain (editora), Debating Immigration, Nueva York, Cambridge University Press.

Massey, Douglas S. et al. (1998), Worlds in Motion: Understanding International Migration at the End of the Millennium, Oxford, Clarendon Press.

Massey, Douglas S., Jorge Durand y Nolan J. Malone (2002), Beyond Smoke and Mirrors: Mexican Immigration in an Era of Economic Integration, Nueva York, Russell Sage Foundation. 
Massey, Douglas S. y Karen A. Pren, «Unintended consequences of us immigration policy: Explaining the post-1965 surge from Latin America», Population and Development Revierw, volumen 38, número 1.

NeE, Victor y Brett de Bary Nee (1973), Longtime California: A Documentary Study of an American Chinatown, Berkeley, University of California Press.

North, Douglass C. (1990), Institutions, Institutional Change, and Economic Performance, Cambridge, Cambridge University Press.

Østergaard-Nielsen, Eva (2001), «Transnational practices and the receiving state: Turks and Kurds in Germany and the Netherlands», Global Networks, volumen 1, número 3.

PASsel, Jeffrey S. (2009), «The economic downturn and immigration trends», lecture delivered at the Center for Migration and Development, Princeton University, 26 marzo, http://cmd.princeton.edu/papers.shtml.

Pew Hispanic Center (2011), «Statistical portrait of the foreign-born population of the United States», 〈http://pewhispanic.org/factsheets».

Portes, Alejandro (1976), «Determinants of the brain drain», International Migration Review, volumen 10, número 4.

Portes, Alejandro, Cristina Escobar y Renelinda Arana (2008), «Bridging the gap: Transnational and ethnic organizations in the political incorporation of immigrants in the United States», Ethnic and Racial Studies, volumen 31, número 9.

Portes, Alejandro, Cristina Escobar y Alexandria Walton Radford (2007), «Immigrant transnacional organizations and development: A comparative study», International Migration Review, volumen 41, número 1. Portes, Alejandro, William Haller y Luis E. Guarnizo (2002), «Transnational entrepreneurs: An alternative form of immigrant adaptation», American Sociological Review, volumen 67, número 4.

Portes, Alejandro y Ruben G. Rumbaut (2006), Immigrant America: A Portrait, Berkeley, University of California Press.

Roberts, Bryan R., Reanne Frank y Fernando Lozano-Asencio (1999), 
«Transnational migrante communities and Mexican migration to the United States», Ethnic and Racial Studies, volumen 22, número 3.

Romero, Roberto Chao (2010), The Chinese in Mexico, 1882-1940, University of Arizona Press.

Sánchez, Martha J. (2007), «La importancia del sistema de cargos en el entendimiento de los flujos migratorios indígenas» en Marina Ariza y Alejandro Portes (editores), El País Transnacional, México, Instituto de Investigaciones Sociales, UnAm.

SaXenian, Anna Lee (2002), Local and Global Networks of Immigrant Professionals in Silicon Valley, San Francisco, Public Policy Institute of California. (2006), The New Argonauts: Regional Advantage in a Global Economy, Cambridge, Harvard University Press.

Saxton, Alexander (1971), The Indispensable Enemy: Labor and the Anti-Chinese Movement in California, Berkeley, University of California Press.

Shaiken, Harvey (1994), «Advanced manufacturing and Mexico: A new international division of labor?», Latin American Research Review, volumen 29, número 2 .

Smith, Robert C. (2005), Mexican New York: Transnational Worlds of New Immigrants, Berkeley, University of California Press.

Stark, Oded (1991), The Migration of Labour, Cambridge, Basil Blackwell. Thomas, Brinley (1973), Migration and Economic Growth: A Study of Great Britain and the Atlantic Economy, Cambridge, Cambridge University Press.

Vertovec, Steven (2004), «Migrant transnationalism and modes of transformation», International Migration Review, volumen 38, número 3. (2009), Transnationalism, Nueva York, Routledge.

Vermeulen, Floris (2005), «Organizational patterns: Surinamese and Turkish associations in Amsterdam, 1960-1990», Journal of Ethnic and Migration Studies, volumen 31, número 5.

Zноu, Min (1992), Chinatown: The Socioeconomic Potential of an Urban Enclave, Filadelfia, Temple University Press. 
(2009), Contemporary Chinese America: Immigration, Ethnicity, and Community Transformation, Filadelfia, Temple University Press. (2010), «Traversing ancestral and new homelands: Chinese organizations in the United States and hometown development in China», Reporte final, Center for Migration and Development, Princeton University, «http://cmd.princeton.edu/papers/wp1002.pdf». 